\title{
Exploring the Magic Cottage: A Virtual Reality Environment for Stimulating Children's Imaginative Writing
}

\author{
Marianne Patera*, Steve Draper ${ }^{\mathrm{b}}$ and Martin Naef \\ Digital Design Studio, Glasgow School of Art, U.K.; University of Glasgow, U.K.
}

This paper presents an exploratory study that created a Virtual Reality Environment (VRE) to stimulate motivation and creativity in imaginative writing at primary school level. The main aim of the study was to investigate if an interactive, semi-immersive Virtual Reality (VR) world could increase motivation and stimulate pupils' imagination in the context of a writing task that is part of normal school practice and of the national curriculum. The study was defined in close collaboration with the head teachers and teachers of two Scottish primary schools so that the implementation of the VRE fitted the needs of the curriculum. The impact of the VRE on the educational activity was evaluated through a formal assessment of the stories by an independent marker, quantitative and qualitative analysis of the stories, and observations and interviews with the teachers. This paper provides a description of the graphical environment and the technology used in the trials, presents our method, results, and experiences. It is suggested that to interpret the observations, and make further progress in both research and practice, it may be important to identify and support three subskills of "imaginative writing" separately: creative imagination, recalling and structuring what to say, and language skills.

Keywords: Virtual Reality; Imaginative writing; Primary school education; Creativity

\section{Introduction}

The study presented here was part of a larger research project ${ }^{1}$ that investigated the use of $3 \mathrm{D}$ digital technologies for enhancing teaching and learning, and for promoting creativity. It was important to choose an educational subject where existing learning and teaching methods can be problematic or inadequate for its instruction/delivery and identify how such technology can help to overcome problems or augment current teaching techniques (Draper, 1998).

This study was primarily exploratory, seeking to develop possibilities for the use of immersive VR technology in teaching writing to pupils in primary schools, partly because educational work with this type of technology had been mostly focussed on science related subjects. We decided to use a field trial with children and teachers as part of their normal curriculum work to explore the prospects for any real educational deployment: in other words to give priority to validity (a realistic context for its use) over demonstrating a pre-determined effect

\footnotetext{
${ }^{*}$ Corresponding author. Glasgow School of Art, Digital Design Studio, House for an Art Lover, 10 Dumbreck Road, G41 5BW, Glasgow, U.K.

Email:m.patera@gsa.ac.uk
}

${ }^{1}$ The ASII-3D (Art \& Science Interactive Initiative 3D) was funded by NESTA and Scottish Enterprise. 
under artificial conditions. An alternative strategy would have been to develop a demonstrable effect in highly artificial conditions e.g. taking children out of class for special treatment with researchers, then train the teachers to play the part of researchers, then attempt to embed the new procedure into scheduled lessons. The latter strategy can probably show educational gains at every stage, but it will not address whether these can ever be applied in normal schools until the last stage. The strategy we used is more likely to discover the key issues in relating the new approach to the real school context early on, and so to guide further research; conversely it is also less likely to show definite gains until a late stage.

The subject matter for this experiment was therefore selected after close consultation with the head teachers and teachers of the two Scottish primary schools that participated in the trials, to ensure that the implementation of the technology fitted the needs of the curriculum. The subject of English language, and in particular the task of imaginative/descriptive writing, was therefore chosen for evaluating the impact of the technology on motivation and creativity.

The idea, as it emerged from discussions between the teachers and us, was to promote imagination and creativity, as opposed to technical skills such as spelling and grammar. This not only seemed to relate to something the technology might offer (the vividness and engagement that VR can give), but to an issue that was relatively neglected in the current educational climate.

Our intent was to create an environment that pupils could explore naturally without having to learn a complex user interface. Hence, by drawing inspiration from fairytales, we designed and modelled a Virtual Reality Environment (VRE) that incorporated numerous interactive features and sound effects. A more detailed description of the environment and the trials follows in the subsequent sections of the paper. Finally, the impact of the VRE on the educational activity was evaluated based on our observations and on formal assessment and comparison to previous schoolwork.

\section{Creating a VRE for Imaginative Writing}

\subsection{VREs in Primary School Education}

Immersive and semi-immersive VREs use high-end equipment, large immersive projection systems such as a CAVE (Cruz-Neira et al., 1993), head-mounted displays, haptic technology and surround sound systems. Datagloves and datasuits allow users to interact with the environment by tracking their motion and providing tactile feedback. Recent and on-going developments in the technology of VR have substantially reduced its cost resulting in a wider exploitation of its abilities as a training tool and educational medium (at primary, secondary and tertiary levels).

The majority of the educational VR projects have been developed for high school pupils and university students with only a few relating to primary school education. Here we cite a number of VREs that have been created specifically for primary school pupils. The Electronic Visualisation Laboratory developed NICE, an immersive multi-user learning environment, in which pupils can create their own virtual garden and control weather conditions and time, for exploring complex ecological interrelationships (Roussou \& Gillingham, 1998). The same research lab created a VRE called "Round Earth Project" to transform younger children's mental model of the shape of the Earth (Johnson et al., 1999).

The Human Interface Technology Lab designed "Virtual Puget Sound" to simulate the processes of the ocean such as tides, currents and salinity (Winn, 2002). Another research project that uses VR, the "Virtual Playground", allows children to design and build their own virtual playground while solving mathematical fraction problems (Roussou \& Slater, 2005). A more recent study that evaluated the impact of 3D VR 
simulations on science education showed that significant pedagogical benefits can be achieved from the proper deployment of such technology (Kim, 2006).

The evaluation of these educational VREs has demonstrated that such technology can help in situations in which concepts are abstract (i.e. ecosystems, photosynthesis, tides, fractions, etc.). In most cases, VR has been utilised to conduct science labs for situations that can not be experienced physically. Intrinsically, this type of learning environment is highly constructivist in nature as it enables the learner to experiment and interact directly with the information or concepts (Winn, 1997).

Furthermore, most studies have reported an increase in students' motivation for the learning task when performed in a VRE, and undoubtedly learning is more likely to occur when students are motivated and engaged by the learning environment. In addition, a VRE can support collaboration and shared experiences since a number of users can simultaneously participate in it. On the other hand, a personal computer is designed for solitary operation where collaboration is only feasible through a network and discussion among users usually happens via text-dialogue boxes (chat). A group activity can have a great impact on learning by encouraging further discussion and increasing motivation (Vygotsky, 1978).

However, Youngblut, in her extended review of educational VREs, reports that the majority of these have been designed for science education rather than the arts (Youngblut, 1998). Moreover, research in this area is still experimental and most of the projects have not been designed to suit the immediate needs of the schools' curricula. Unlike previous studies, this project examines the impact of a VRE on a non-science area, such as English language, and more specifically on imaginative writing. Note that this VRE has been developed to address the needs of the current school curriculum and that the experiment did not intend to evaluate the technology nor the individual properties of VR (i.e. presence, interactivity and navigation). We opted for a VRE in order to create a more immersive and shared experience. A desktop system is not suitable for multiple viewers whereas a VRE can be experienced by more than two viewers simultaneously. We also anticipated that an immersive system would make the experience more vivid and that would eventually engage and inspire pupils. Our intention was to create a 3D imaginary world that groups of pupils could collaboratively explore and interact with by keeping the system's interface as transparent as possible.

\subsection{Imaginative writing}

Imaginative writing is part of the English language subject. This activity is typically conducted once or twice a fortnight in the classroom, taking about 40 minutes after a briefing or other introduction by the teacher. According to the Scottish National Curriculum, there are three types of writing: Functional (Letter, Leaflet, Report, News Article), Personal (Account, Report, Letter) and Imaginative (Poem, Story, Imagined personal response to a given topic/context). In addition, as it appeared from this study, there are learning aims focusing initially on technical language skills and secondly on expressive skills to do with creativity.

Recent educational agendas have attempted to give more prominence to content and structure and rather less to grammar, spelling and handwriting. Thus, teachers have devised a number of methods and mechanisms to engage pupils' interest and challenge their thinking. Storytelling has been used to stimulate imagination, and drama and role-play have been introduced to create inspired contexts. Furthermore, the government is encouraging the use of media and ICT. Consequently, the deployment of all the suggested strategies requires careful planning, ICT knowledge and occasionally further training for acquiring certain skills.

Whilst several online resources have been designed to aid teachers by offering interesting ideas for their English classes $^{2}$, educational researchers are constantly developing interactive virtual environments to augment learning and teaching, and engaging pupils' interest. Most of these are desktop computer applications running either from

\footnotetext{
2 www.teachingideas.co.uk/, www.primaryresources.co.uk/index.htm, www.bbc.co.uk/schools/
} 
a CD or DVD or online. "Teatrix", for instance, is a graphical virtual environment designed to support story creation through role-play (Prada et al., 2000). Another research project that aims at promoting educational drama as a preparatory activity prior to the actual writing task is "Ghostwriter" (Robertson \& Oberlander, 2002). Both Teatrix and Ghostwriter allow children to act out a story within the virtual environment, using role-play as as preparation for story-telling and with a focus on the social interaction inside and with the virtual world, whereas our experiment explored how inspiration from a more immersive experience can be transferred into a different medium. Similarly, the "PUPPET" project (Marshall et. al., 2004) focused on improvisational play within the virtual environment in order to support reflection about aspects of narrative. Interaction within our virtual environment is purely exploration with the creative writing process as a follow-on activity.

While no applications have been found involving VREs for directly supporting writing at primary school level, several experimental projects have produced mixed reality environments by combining physical rooms with bigscale 2D projections for immersing children in virtual story spaces (Watson et al., 2004; Bodick et al., 1999). The KidStory project (Stanton et. al., 2001) introduced new interfaces and concepts for collaborative story creation, with most of their technology focus being on interactive, collaborative drawing and sketching environments in order to develop stories without the potential inhabitation of the mechanical aspects of writing. The aforementioned projects focused primarily on promoting aspects such as character development, storytelling, setting description, etc. and less on technical writing skills.

This paper presents the Magic Cottage, a graphical, semi-immersive collaborative VRE, not designed to tell a story but to inspire pupils to write their own stories by using it as a setting or a starting point. The rationale behind the choice of developing a custom environment and not using an existing computer game was that we did not want to involve any characters or a predefined plot. The teachers thought that the presence of characters was not important for the specific task of imaginative writing as the pupils were expected to create their own story and develop their own characters. The pupils had the freedom to explore the 3D model without completing any specific tasks (unlike "puzzle games", failing to activate or find an object does not influence the flow of the exploration).

Some computer games allow users to create their own 3D worlds by using a library of landscapes and 3D models (e.g. Neverwinter Nights) that does not require modelling or programming skills. A custom 3D environment allowed us more control over the design of the $3 \mathrm{D}$ elements, navigation and interaction with the objects. The VRE offered the setting in which the stories would take place. Some unusual and "out of place" objects have been introduced with a view to make the environment more interesting, to provoke questions and to generate imaginative interpretations (e.g. the spiders and coins in the chest, the diary, the strange bottle in the closet, the tiny bed next to the normal-sized bed, etc.) Thus, the Magic Cottage offers free exploration and interaction with virtual objects, within a life-size fairytale setting.

\section{Method}

\subsection{Participants}

Two primary schools took part in this study: Primary School 1 (primary 7 pupils) and Primary School 2 (primary 6 pupils). The trials were arranged in the first instance through the West Dunbartonshire education authority in Scotland, within whose area the primary schools are. 


\subsection{The technology}

A semi-immersive projection system was used to present the virtual environment. The children were standing in front of a $1.8 \times 1.3 \mathrm{~m}$ wide projection screen with an active stereo CRT projector behind, wearing Crystal Eyes stereo goggles to provide a separate image for left/right eyes for stereoscopic depth perception. The system was driven by a standard high-performance PC.

The pupils used a joystick to navigate within the environment. Although more sophisticated input devices were available, we chose the joystick because many children are already familiar with the concept from previous gaming experience. Often, interface usability and technical issues can be significant obstacles for learning to occur and getting familiar with a new interface can take longer than expected (Johnson et al., 1999). Even though the environment supports multi-user experience and collaboration, the navigation can be controlled by only one user at a time; the other pupils gather around the person controlling the simulation. Although correct perspective can only be generated for a single viewpoint due to the inherent limitations of stereoscopic rendering, the display used for our experiments is large enough to provide an experience similar to commercial 3D cinema projections (e.g. IMAX 3D). Pupils can vocally guide the person who has the joystick, which enhances the sense of being a member of an exploration team set for a 3D journey.

The virtual environment was modelled using a standard 3D design package (Maya) and displayed using an existing virtual reality toolkit (blue-c API) to enable rapid application development (Naef et al. 2004). The application is configurable to suit a large range of presentation systems, from a laptop computer up to fully immersive environments such as a CAVE and can easily be deployed to schools for further experiments using a portable projection system.

\subsection{The design of the environment}

The theme of the VRE had been chosen after a brainstorming session that involved the head teachers of both primary schools. Based on how imaginative writing is taught in the classroom as part of the curriculum, they gave some very constructive suggestions regarding the atmosphere and interactions of the VRE. For example, the use of sound effects was considered very important for conveying the feeling of presence (Jelfs \& Whitelock, 2000). We decided not to portray any animated characters for the following two reasons: first, the teachers believed that the presence of humans or other creatures was not essential for the writing task as they wanted the pupils to use their imagination to make up their own characters. Secondly, it would have significantly increased the time required to create the 3D model and integrate the animations into the VR toolkit, therefore exceeding the allocated project budget.

In turn, it was decided that two exposures to the VRE would provide clearer evaluation results, since the first exposure might show mainly effects of novelty or unfamiliarity. The first session also served as an introductory demonstration of the technology and the navigation controls, therefore it did not involve difficult manoeuvres and many interactive objects. The pupils saw two different scenes in the VRE: in the first session the outside of a cottage and its surroundings and in the second session the interior.

First Session - Outside the Cottage: In the first session, the pupils find themselves outside a Cottage (Fig. 1a). The teacher assigns them the role of an expedition team that has been travelling through a dark forest and suddenly discovers this cottage. They are then prompted to explore the "Magic Cottage". A dreamy and mysterious track had been chosen for background music, along with realistic sound effects of wind, birds and water stream (near the well). Since the pupils are not able to open the cottage's main door to get inside, they begin a search for keys and clues. They can open the woodshed door, explore all the objects, read the labels on the vials and boxes, open a book, and pick up a key (Fig. 1b). After careful exploration they can find a bottle of poison under a tree. 

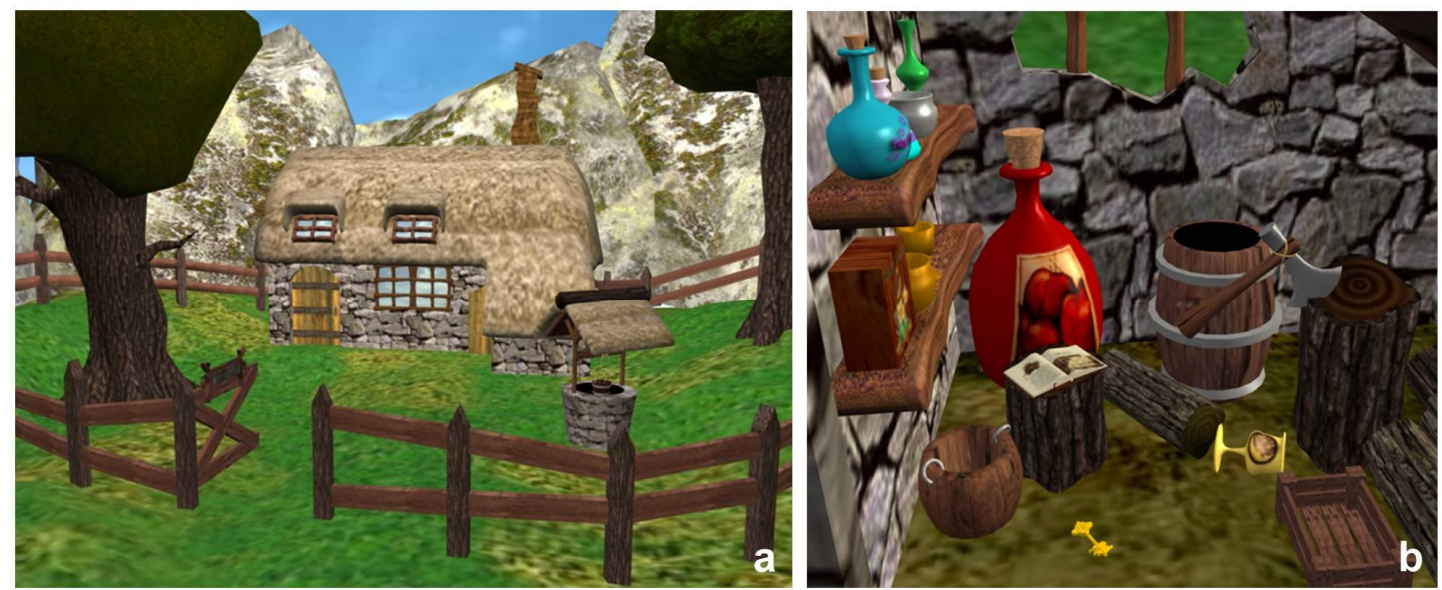

Figure 1. a) The exterior of the Magic Cottage b) Various interactive objects in the woodshed

Second Session - Inside the Cottage: The second session takes place in the interior of the cottage (Fig. 2). This was designed to be graphically richer, involving more interactive objects and sound effects, namely the crackling fireplace, the boiling greenish liquid inside the cauldron, the noise of lizards, the snoring coming from the bedroom, the creepy laughter and the background music. All these create a "spooky" and dramatic atmosphere, and heighten the anticipation and mystery.
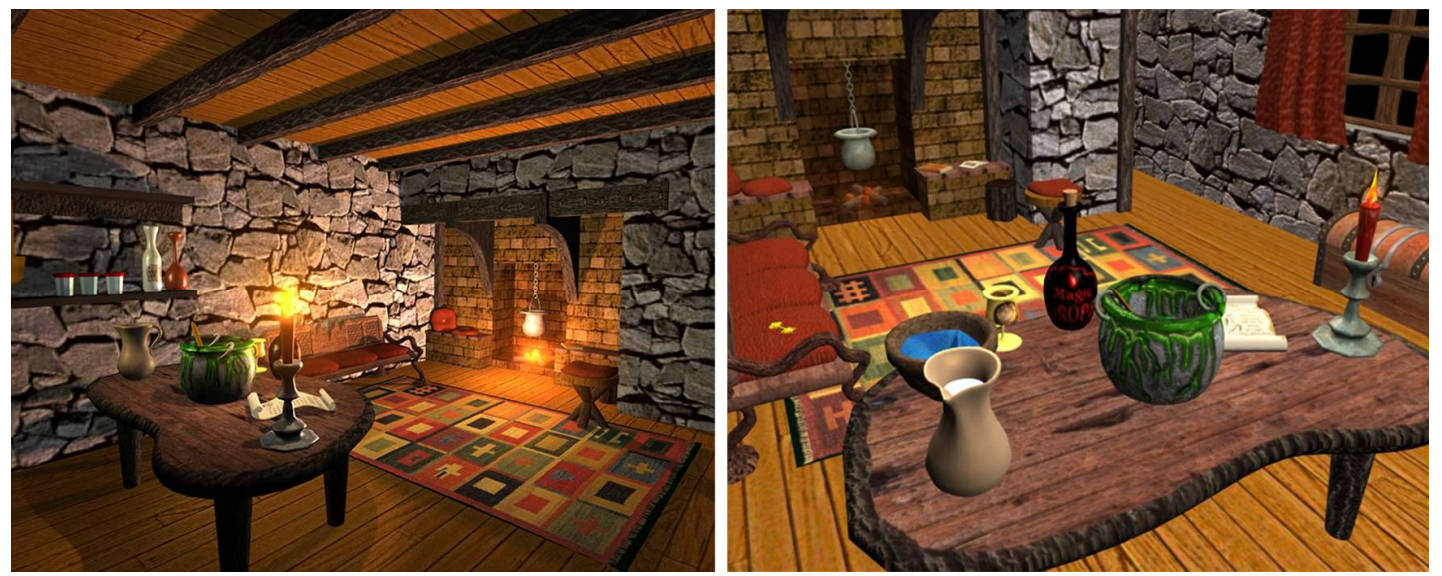

Figure 2. Screenshots of the interior of the Magic Cottage

\subsection{The experiment}

This study compared three groups of pupils: the digital group (six pupils from each school) who travelled twice to the Digital Design Studio (DDS), where the VR facilities are housed, and experienced the virtual model, the non-digital group (another six pupils from each school) who also travelled twice to the DDS but did not see the virtual environment before writing (thus offering a control for the excitement, attention and sense of being involved, yet without in fact using the technology) and a stay-behind group (12 pupils from each school, of which six were selected for detailed comparison of their work) who had the usual writing exercise with a teacher at their schools.

This allowed us to compare two schools, three different intervention groups (digital, non-digital, stay-behind) and three stories: two associated with visits to the DDS (Outside the cottage, Inside the Cottage) and a 
comparison drawn from a previous piece of imaginative writing (the Deserted Island) as seen in Table 1. The group members were chosen by the head teachers to achieve a similar mix of high, medium and low ability children, and similar numbers of boys and girls to each group, thus using a form of stratified random sampling. Every child produced a piece of written work on each of the three occasions: 108 stories in total. These produced various measures described below.

After the arrival of the groups at the DDS, the digital group was taken to the VR room. They were then given the 3D glasses and a brief introduction regarding the VRE. In the first session we gave the joystick to one of the pupils. However, two of the pupils felt nauseous during that session. This was probably the result, firstly, of being forced to experience motions they were not controlling themselves and secondly, of the violent motions, which in turn were probably due to inappropriate transfer from computer games controls, which are less sensitive in terms of the "gearing" ratio between joystick and apparent visual motion of the image. On subsequent occasions, it was therefore decided that a researcher would have the controls at first and navigate around the environment by following the pupils' directions, which led to a more successfully systematic navigation of the VRE. Navigation was performed in a slower pace, especially in the beginning of each session. The controls were handed to the pupils for the last seven minutes of the session and every child was given the chance to navigate.

The non-digital group was taken to the meeting room (desks and chairs had been rearranged to recreate the classroom environment). Each VR session lasted for 20 minutes. During that time the teacher was conducting the usual writing lesson with the non-digital group. The lesson normally involves a group discussion on the topic that the teacher raises and pupils' ideas are written on a whiteboard (Fig. 3). The teacher encourages them to close their eyes and imagine themselves in a setting (in this occasion a Magic Cottage). Then asks them to tell her what they can feel, smell, hear, touch, etc. Often, the teachers will use visuals such as photos, paintings and drawings.

After the VR session, the digital group sat in the meeting room at a separate table from the non-digital group. Then the writing exercise lasted for approximately 50 minutes. The pupils who had seen the VRE were told not to mention or describe it to the other children. For evaluation purposes, the stories were formally assessed by an external marker while additional qualitative data were collected through other means. In particular, all VR sessions were video recorded (including audio) as the lighting and layout of the VR room did not allow the researchers to keep notes. The footage, which was analysed afterwards, provide us with useful information about the way pupils collaborated in the VRE, the level of immersion they experienced and signs of oral storytelling (discussed in section 4.5). A researcher was assigned to observe the non-digital group during the lesson with the teacher and during the writing task by keeping notes. Another researcher was observing the behaviour of the digital group during the discussion and the writing task. We had also asked the teachers to point out to us any "unusual" behaviour they may detect as they were more familiar with the pupils' normal behaviour during this task. On a previous occasion one of the researchers had visited the schools and observed how the lesson was conducted in class, which gave us an indication of how the lesson was carried out with the stay-behind group. Furthermore, a week after the trials, a researcher visited the schools and interviewed the head teachers and teachers who took part in the activity in order to capture the overall impact of the experience on the pupils but also on the teachers. 
Table 1 . The design of the study

\begin{tabular}{|c|c|}
\hline \multicolumn{2}{|c|}{ Week 1 (no intervention) } \\
Story 1: Deserted Island \\
\hline Day 1 & Day 3 \\
\hline Primary School 1 & Primary School 2 \\
\hline Digital group - School & Digital group - School \\
Non-digital group - School & Non-digital group - School \\
Stay-behind group - School & Stay-behind group - School \\
\hline \multicolumn{2}{|c|}{ Week 2 (intervention) } \\
Story 2: Outside the Cottage \\
\hline Day 8 & Day 10 \\
\hline Primary School 1 & Primary School 2 \\
\hline Digital group - DDS & Digital group - DDS \\
Non-digital group - DDS & Stay-behind group - School \\
Stay-behind group - School & Week 3 (intervention) \\
\hline \multicolumn{2}{|c|}{ Story 3: Inside the Cottage } \\
\hline Day 15 & Day 17 \\
\hline Primary School 1 & Primary School 2 \\
\hline Digital group - DDS & Digital group - DDS \\
Non-digital group - DDS & Non-digital group - DDS \\
Stay-behind group - School & Stay-behind group - School \\
\hline
\end{tabular}

\section{Results}

Both groups that visited the studio enjoyed the outing and especially the digital group got very engaged in exploring the VRE. The variables that this study aimed to measure and evaluate were motivation and creativity. Motivation was gauged both quantitatively by word count of the pupils' stories and qualitatively from the video recordings, observation data and teachers' comments. Each piece of children's writing was marked by an independent teacher, and we additionally assessed them against other criteria such as description of senses and emotions, storyline, fantasy, sequence of events, etc. The outcomes of this analysis are discussed in section 4.3. 


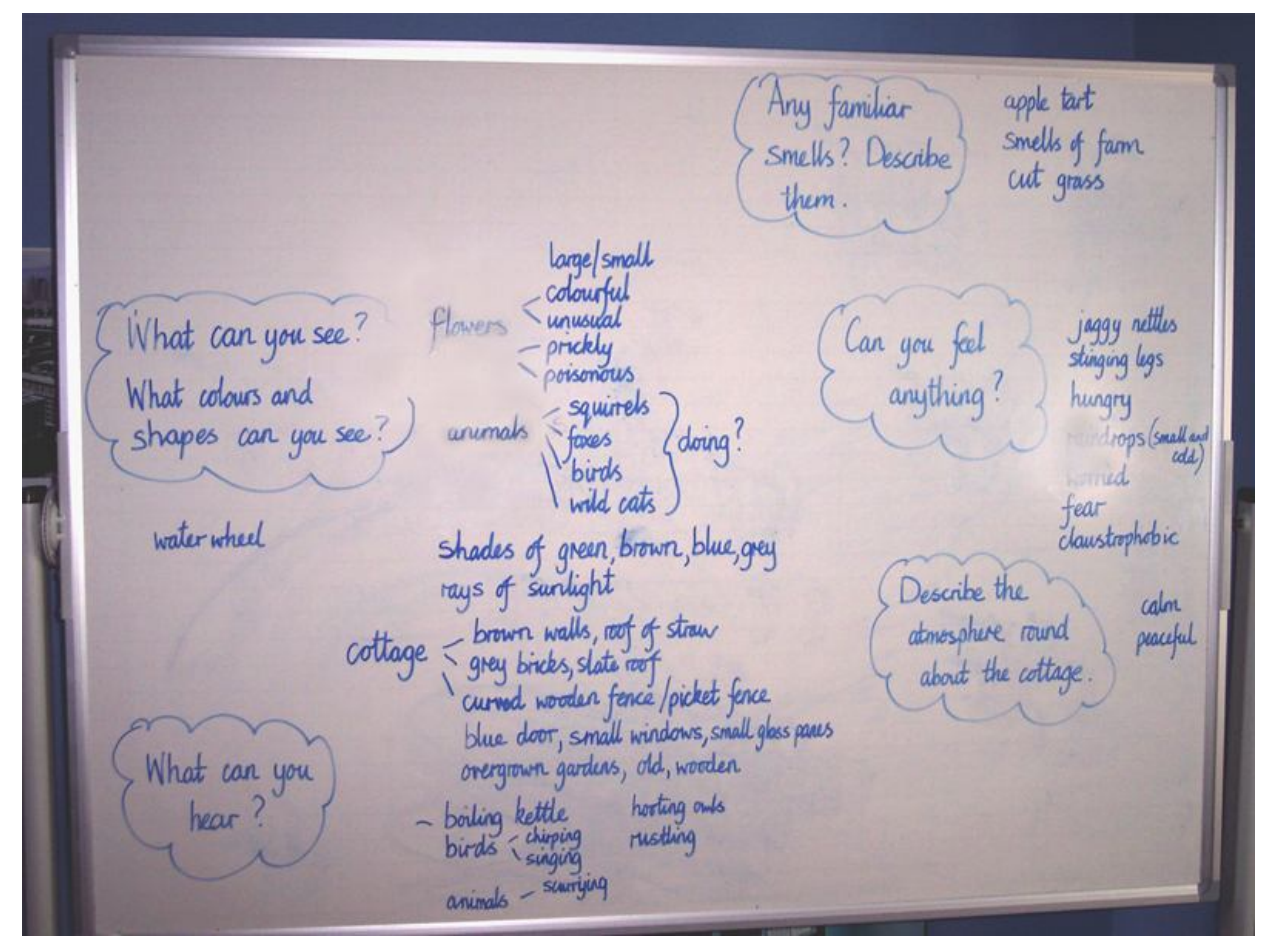

Figure 3. During the group discussion the teacher writes some key words on the white board

\subsection{Formal Marking Scheme}

An external teacher was selected to mark the work of all the participants from both schools, and for maximum validity in terms of relevance to current practice, used the national assessment criteria. A list of the criteria for assessing English extended writing can be found at the National Assessments 5-14's webpage http://www.aiflna.net/na/guid_eng.aspx\#extendwritingcriteria. The levels range from A to E (A being the lowest level) and then from $\mathrm{A} 1$ to $\mathrm{A} \overline{2}$ to $\mathrm{A} 3$ (again A1 being the lowest). However, pupils who have reached level A3 for example should be assessed according to the criteria of level B and so on. There are four main categories of criteria: 1) Choice and use of language, 2) Related technical skill: spelling, 3) Selection and organisation of ideas and 4) Related technical skill: punctuation. These sets of criteria are further divided into subcategories depending on the level.

The teacher who marked the stories for this study provided us with two different assessment sheets for each pupil: one that was more focussed on language, grammar, sentence structure and included 14-18 criteria, and one that was more targeted on imaginative writing which only included 5 more vague criteria, such as use of unusual and more sophisticated words, use of a range of senses e.g. see, hear, smell, etc. However, it seemed that the first assessment sheet was actually determining the grades of the pupils. Hence, the formal marking of the stories did not provide us with clear results regarding the imaginative aspect of the written pieces, which was the focus of this study, or demonstrated any systematic differences between groups. As shown in Table 2 and Table 3, no significant patterns were discernible using this scale.

Even though the project had focused on designing and building a VRE to suit the learning aim of promoting creativity and imagination, the formal assessment criteria were not flexible enough to allow measurement of more abstract and less technical aspects of writing. Whilst recent educational guidelines are emphasising the importance of creativity in schools, the marking scheme does not seem to reflect that. This becomes even more 
apparent when informal learning environments are introduced into the formal educational setting. In such cases, new evaluation methods would have to be deployed to gauge the potential educational benefits.

Table 2. The mean and standard deviation of the pupils' grades

\begin{tabular}{|l|l|l|}
\hline & Mean & SD \\
\hline Story 1 (Deserted Island) & 2.75 & 0.97 \\
\hline $\begin{array}{l}\text { Story 2 (Outside the } \\
\text { Cottage) }\end{array}$ & 2.36 & 0.82 \\
\hline Story 3 (Inside the Cottage) & 2.76 & 0.95 \\
\hline \multicolumn{2}{|l}{} \\
\hline Digital groups & 2.73 & 0.9 \\
\hline Non-digital groups & 2.59 & 0.89 \\
\hline Stay-behind groups & 2.52 & 0.99 \\
\hline \multicolumn{2}{|l}{} \\
\hline Primary School 1 & 2.82 & 0.94 \\
\hline Primary School 2 & 2.43 & 0.88 \\
\hline
\end{tabular}


Table 3. Formal assessment scores. Each line represents one pupil (with its own colour and marker shape) showing the scores for the three stories they wrote, with a separate chart for each of the six groups in the study. Group means are shown in table 2.

Primary School 1

digital group

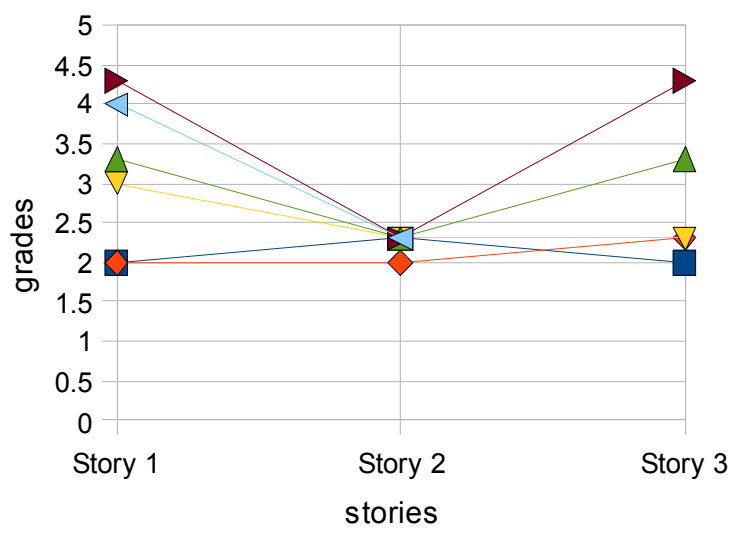

Primary School 1

non-digital group

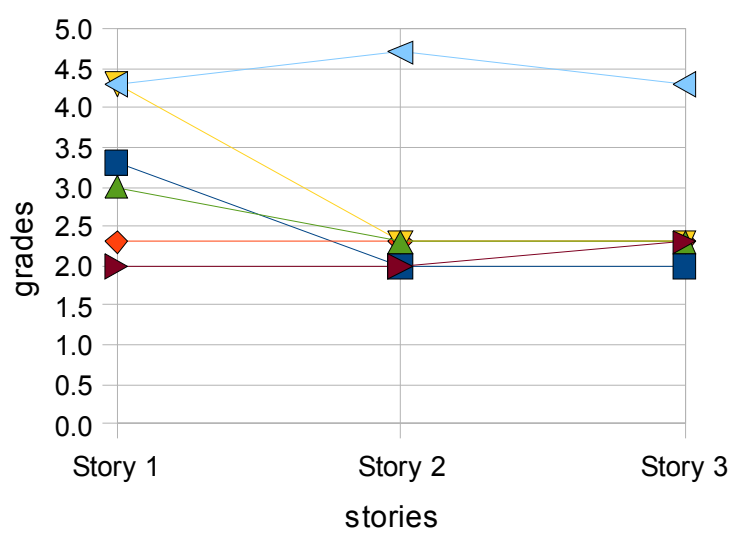

Primary School 1

stay-behind group

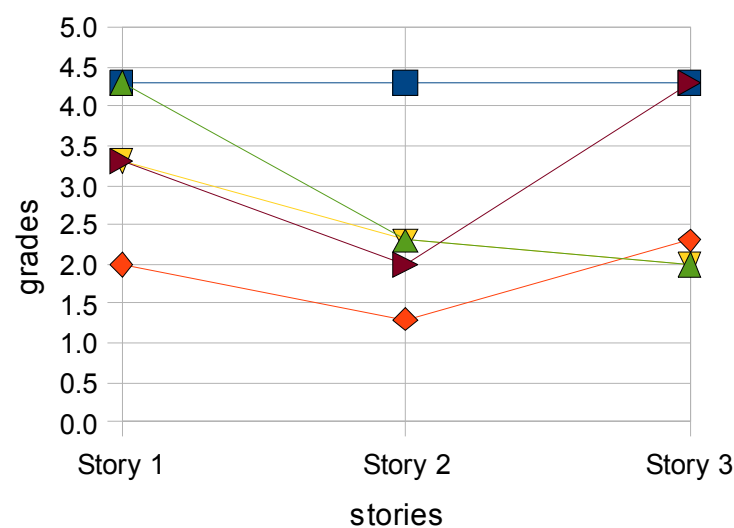

Primary School 2

digital group

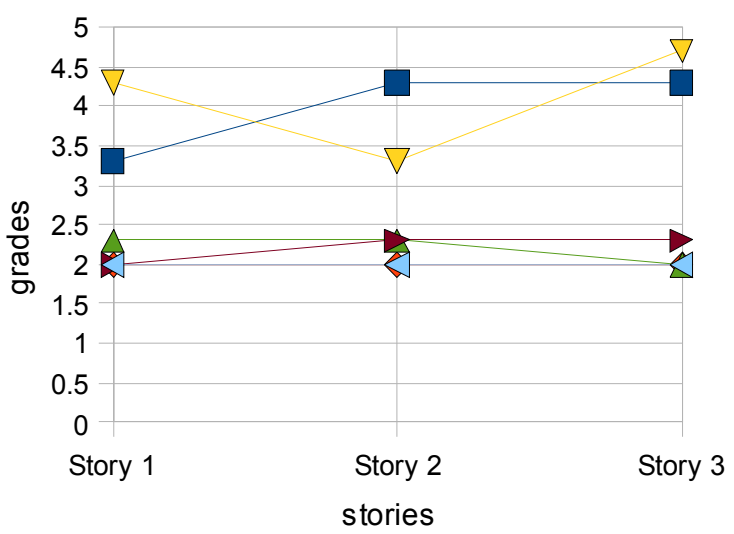

Primary School 2

non-digital group

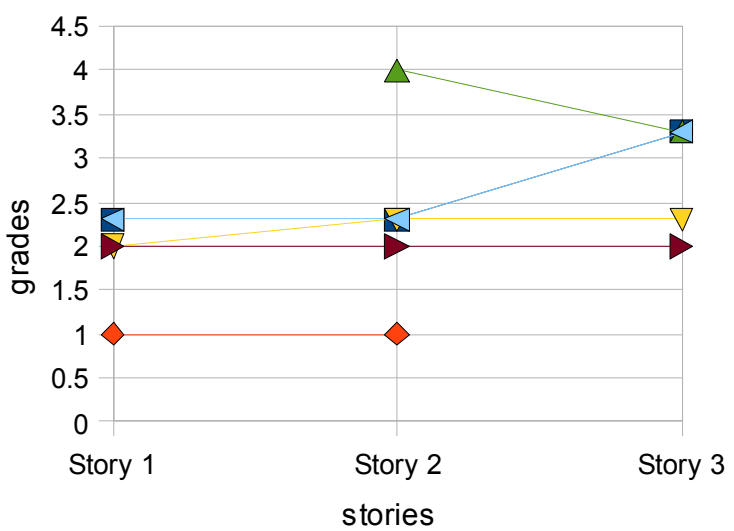

\section{Primary School 2}

stay-behind group

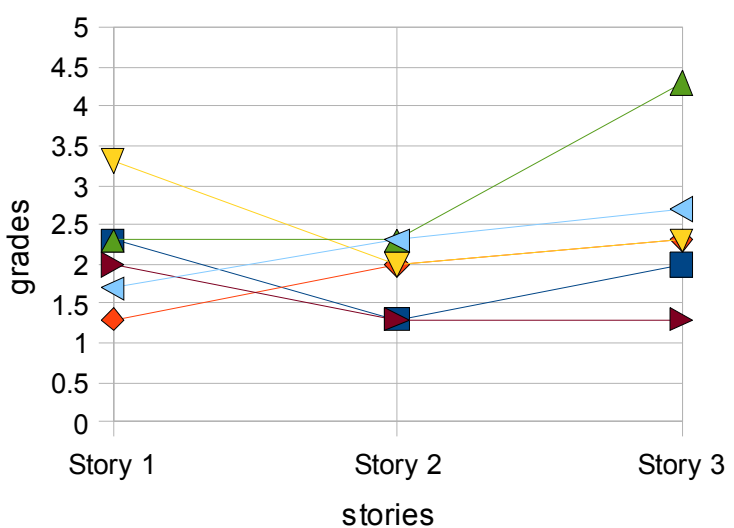




\subsection{Motivation}

The hypothesis that pupils would be more motivated to write after exposure to the VRE was examined based on observations by the researchers and the teachers accompanying the visits. On one occasion, it was noticed that two of the six pupils (one of high and one of low previous writing ability) who had had the VR exposure settled into the writing task much faster than the others - they had covered about $3 / 4$ of a page in 10 minutes when the rest had only written about $1 / 4$ or $1 / 3$ of a page in that time. According to the teachers these two pupils did not normally write that fast. This could be consistent with the notion that the VRE had primed their imagination with plenty to say, and that that had previously been a bottleneck for them.

Furthermore, the teachers noticed that some pupils' behaviour was different from usual. They were more engaged and more focused on the task than normal. The 3D experience seemed to have a stronger effect on boys who are more difficult to engage into writing than girls. Boys often write less than girls and do not get easily motivated, as most topics do not interest them. It appears that the VRE boosted their motivation, increased their engagement in the task and settled them into writing faster than usual.

Although most digital pupils were lively and talkative during the VRE session, a few found it hard to put their ideas on paper and it took them longer than the non-digital group to complete their stories. A possible explanation for this is that the VRE gave this subset of pupils plenty of stimuli, but this also made it harder to choose where to begin and what to include or exclude in their story. Whilst the VRE obviously sparked their interest, this did not get successfully expressed in their writing task.

In addition to the observation data, after a comment one of the teachers made, we conducted a word count of all the stories in order to appreciate whether the intervention had stimulated pupils to write more than they would usually write in class. Table 4 and Table 5 show a comparison of the data between the three groups and between the two schools. Similarly to the grades' analysis, the word count did not show any clear patterns.

Table 4. The mean and standard deviation of the stories' word count

\begin{tabular}{|l|l|l|}
\hline & Mean & SD \\
\hline Story 1 (Deserted Island) & 162.76 & 55.61 \\
\hline $\begin{array}{l}\text { Story 2 (Outside the } \\
\text { Cottage) }\end{array}$ & 188.11 & 50.71 \\
\hline Story 3 (Inside the Cottage) & 194.91 & 49.79 \\
\hline \multicolumn{3}{|l|}{} \\
\hline Digital groups & 187.53 & 57.63 \\
\hline Non-digital groups & 181.31 & 45.31 \\
\hline Stay-behind groups & 176.61 & 57.77 \\
\hline \multicolumn{2}{|l|}{} \\
\hline Primary School 1 & 194.29 & 45.82 \\
\hline Primary School 2 & 170.38 & 57.66 \\
\hline
\end{tabular}


Table 5. Word counts. Each line (with its own colour and symbols) shows the count for the three stories by an individual pupil, with a separate chart for each of the six groups. Group means are shown in table 4.
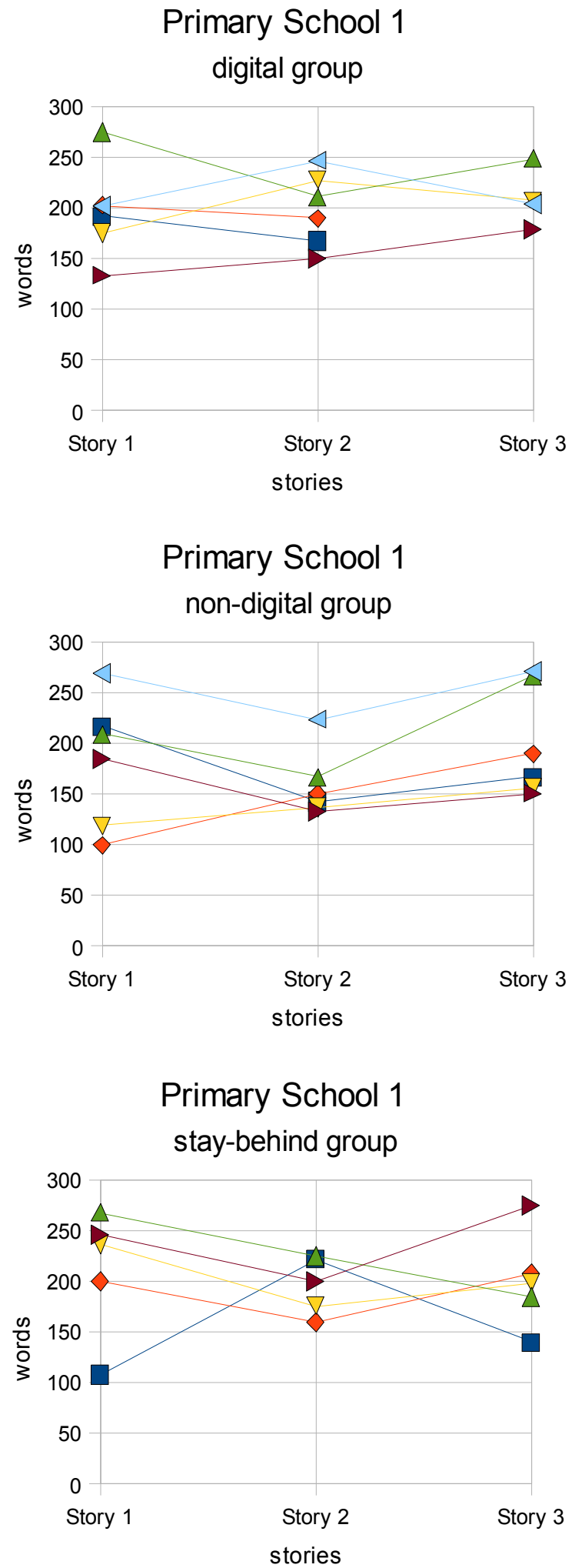
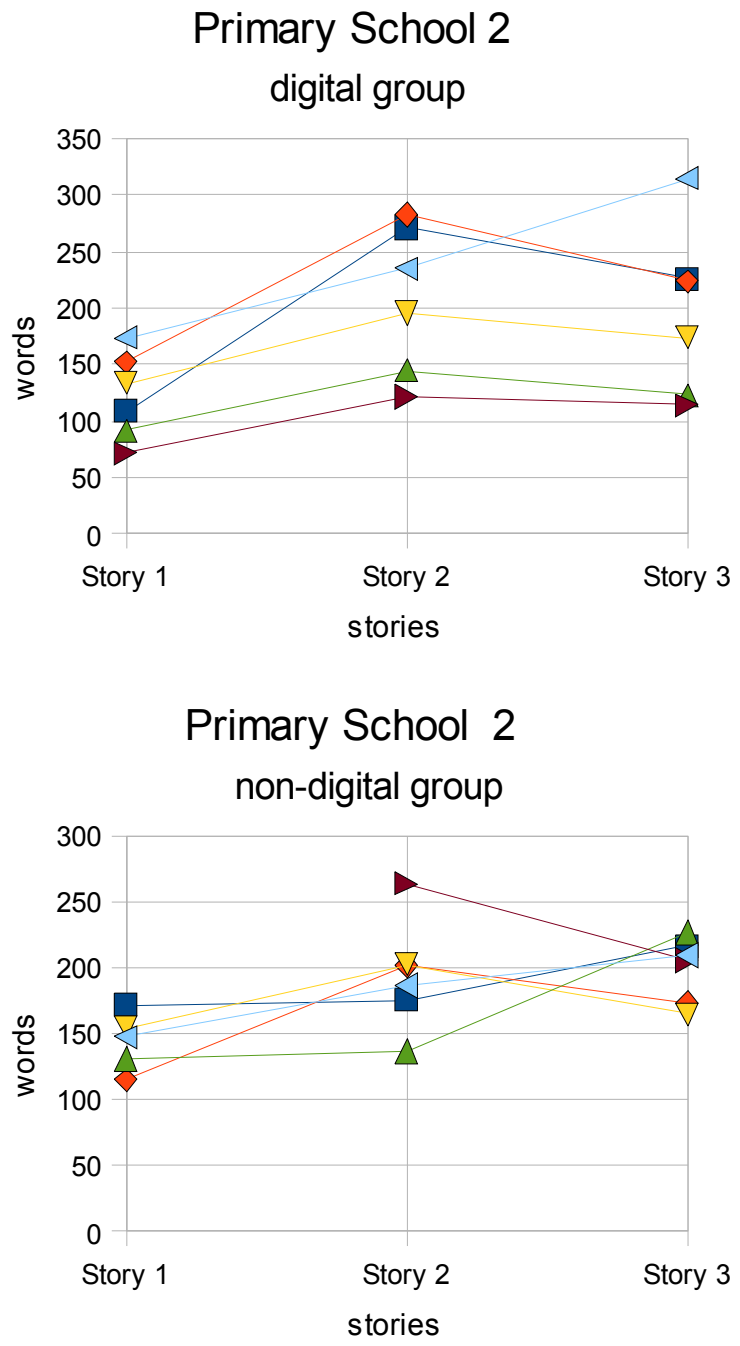

Primary School 2

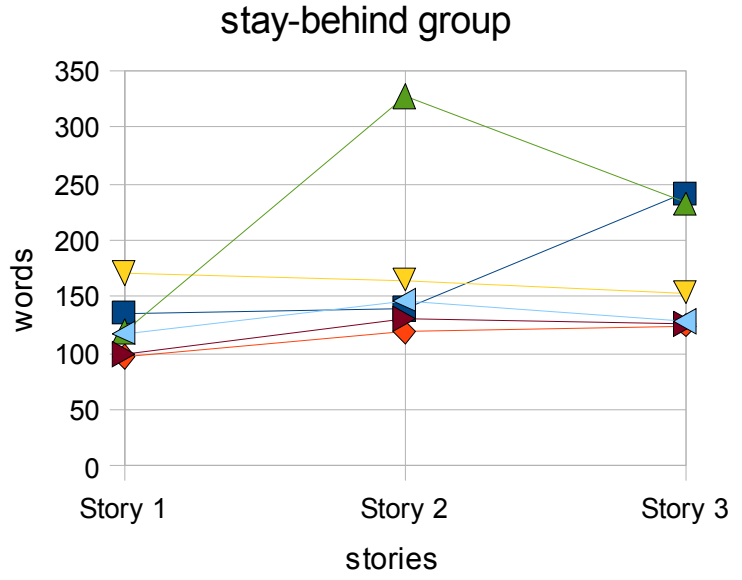




\subsection{Creativity}

As the formal marking of the stories did not provide us with useful data regarding creativity or imagination, we re-examined the stories using a custom scale to allow for a more qualitative analysis of the written works. Other researchers have also come across this issue and therefore had to devise a different method to evaluate pupils' stories by introducing measures that were more appropriate for evaluating the variables under investigation (Robertson, 2001; Amabile, 1985).

Hence, we introduced additional measures such as character development, storyline, emotions, senses, sequence of events and fantasy. For instance we examined whether the pupils had introduced any characters in their story and whether they interacted with them (i.e. dialogue). Only a couple of pupils created a character for the "Deserted Island" task (for obvious reasons as it was deserted), while only in the third task we can see more pupils meeting or encountering characters inside the cottage.

"Next came another door which led to where the voices and laughter were coming. The door slowly opened and there was a group of people talking about their childhood." Stay-behind group pupil.

The storyline criterion gauged the development of a plot for the piece of writing (e.g. not only describing the setting but engaging the reader with an interesting storyline). The emotions and senses measures demonstrated the level of the pupil's participation in the story and the attempt to create an atmosphere for the reader. Interestingly, almost all of the children who experienced the VRE gave very lively descriptions of how they felt and what they could hear, smell and touch. However, the same can be said for the high ability pupils of the other two groups.

"As I closed the door a barrel was laying with no lid so I closed in on it and saw inside there was a red, orange coloured mould that made me want to blow chunks." Digital group pupil.

"The whole cottage was in such an eerie silence I could hear its footsteps. Several moments later I had another bigger shiver up my spine and I also felt I wasn't welcome here.” Stay-behind group pupil.

We introduced the "sequence of events" measure after noticing that the digital group's stories had been influenced by their navigation path inside the 3D world, which made the narrative more linear and easier to follow. Finally, fantasy is probably the criterion that relates most closely to creativity and imagination. Nevertheless, this appeared to be the most challenging measure to quantify and compare. For the digital group's stories we simply examined whether the pupils had introduced elements such as objects, noises, actions, that were not part of the VRE. For the two groups that had not seen the 3D environment we studied whether the pupils had incorporate elements that had not been mentioned during the group discussion with the teacher and had not been written on the whiteboard.

"Laying on the floor was a key. It was as shiny as the sun on water and as gold as coins pirates stole." Digital group pupil.

"This cottage was like a palace. It had chandeliers, diamond chairs, a marble staircase, golden doors and a different type of marble as a floor." Non-digital group pupil.

Nevertheless, even that scale did not show any significant differences between the groups. The low ability pupils seem to have benefited more by the VRE as their stories relating to the Magic Cottage appeared to be more structured and the description of senses and emotions was more vivid. On the other hand, many of the pupils 
have shown improvement in the third story and a reasonable explanation for this could be the result of practice of writing rather than the intervention.

As mentioned previously, the teachers provided an extensive introduction to the writing task (to all three groups, digital, non-digital and stay-behind), not only describing the task but going into details of topics they might describe, and generating a list of key words they might use (Fig. 3). This appeared to aid the digital group by providing them with words to attach to the imagery and sounds of the VRE. A possible explanation is that creative writing requires two different kinds of input: one is the visual image of something worth describing and the other is the verbal means for producing a description. The results demonstrate that this VRE has the potential to stimulate creativity, but that lessons directed at this should perhaps be separate from those directed at improving other aspects of writing.

Nevertheless, there are at least two issues behind the notion of "imagination" here. First is how original (or not) the object of description is: whether it is something experienced or creatively invented. The second is the skill required for translating that idea into words, particularly if the writer is not familiar with any standard way of describing such a thing. The VRE may help with the former, partly by its sensory vividness, and partly by its ability to depict things which do not exist or are hard to encounter in the real world; but this is no guarantee that a given child can find the words to express it, even if it increases their motivation to attempt to do so.

Those who had experienced the VRE had described accurately most of the objects they had seen and sounds they had heard; eventually these stories were very similar in style and words. Surprisingly though the same can be said for the non-digital and stay-behind groups since the pupils used most of the words that had been voiced during the discussion and those written on the board. This can be attributed to the way the tasks had been assigned by the teachers, who evidently put more emphasis on description rather than imagination. According to the attainment targets of the curriculum, imaginative writing entails description of a setting; however no credit is given for creating a storyline.

The teachers asked the pupils to describe the settings (i.e. the Cottage) whereas a different question (e.g. "Who lives in the Magic Cottage?" or "While you are exploring the cottage suddenly the front door bursts open and... What happens next?") could probably have prompted them to create more imaginative plots. The pupils thus believed that if their descriptions are accurate and detailed they would have completed the activity successfully. This was a shortcoming, which was primarily caused by our attempt to carry out this writing activity as the participants would normally do in their classroom as part of their curriculum, without ensuring that the learning aim of exercising imagination was carried through into the instruction given by the teachers.

\subsection{Observations}

We now discuss the numerous open-ended observations, made by either the researchers or the teachers during this study, to provide an insight into primary school pupils' behaviour and attitude toward the VRE.

Both digital groups seemed to enjoy the VR experience and the researchers can confidently report that a high level of immersion had been achieved, even though the system was designed for semi-immersive experiences. The pupils were reacting very naturally, as if the environment was real and they were physically in it. After the first four minutes of being in the VRE, they had completely shut off the real surrounding environment and the external noises, ignoring the presence of the teachers, and of the researchers and their video camera.

They responded very expressively to the sound effects and interactive objects. For instance, when they opened the big barrel and saw what was inside, they all made a grimace of disgust. When they opened the "Lizard Tails" box and heard the creepy noise, they stepped back and shouted "Close the box!". Before opening the closet, one girl had her hands in front of her face, ready to cover her eyes, while most of the kids screamed when the closet burst open. 
Furthermore, this VRE offered them the opportunity to participate in the environment simultaneously and to act as a team and not as individual players. During the analysis of the video footage and the researchers' observation notes, two interesting outcomes emerged: collaboration over both navigation and narration. The reason for choosing groups of six pupils was primarily because of the number of stereo glasses available and the view that exploring the environment as part of a group would create a more pleasant experience. Initially, we were concerned that this could also generate arguments and quarrels in a scenario where certain pupils wanted to take control and navigate as they pleased without consulting with the others. Surprisingly though, pupils collaborated very well, and the sense of being part of a team seemed to engage them even more.

As a result of their excellent collaboration and communication, comments, ideas and thoughts that were voiced during the exploration were beginning to form a narrative. Someone would ask a question (e.g. "Whose house is this?"), then the other pupils would express their opinions and ideas. Since every event in the VRE triggered a new question or comment, a story was naturally constructed by combining each pupil's contribution. Unfortunately, only a few of these ideas were integrated in the subsequent written stories. Further research might identify how collaborative oral narration could be transferred more successfully to the written form.

After their exposure to the VRE, which was an exciting and novel experience, the pupils were confronted with blank sheets of paper that transferred them very abruptly from the magic virtual world and informal learning setting to the real world and formal educational setting. For some of the pupils this harsh transition could have negative effects. Some pupils managed to stay focused and started immediately writing up their stories, whereas for others it was more difficult to concentrate and put their thoughts on paper. How can we integrate this type of technology into the formal learning environment without making the transition from virtual to real and vice versa feel as rough? This problem could be addressed by further research in the area.

\section{Conclusions and Future Work}

The study reported here aimed to be exploratory, not only of the impact of the technology on children using it but also of how it could relate to current school activities and requirements. The trials reported in this paper represent something like "first contact" between VR technology and school learning. On the other hand, and unlike many studies published in the literature related to educational technology, this was not a laboratory demonstration but a trial involving real schools, and the learning aims and tasks were not chosen to suit the technology nor research purposes, but pre-existing ones already nominally part of the curriculum. Here we discuss a possible interpretation of both the lack of a clear pattern in the quantitative results and of some indications in the quantitative observations.

On the surface, the whole intervention was a success. The pupils were, and remained, engaged (and the VRE group the most); the potential difficulties with the technology for both researchers and children were not significant in practice; the teachers remained positive about its perceived value and felt that for a few children there were signs of a large positive effect. Thus it passed the "customer satisfaction" test for both pupils and teachers, who would be happy to see this become part of regular practice. On the other hand, there seems no real indication of a benefit in any of the measures we used. What are the possibilities for interpreting this?

The numbers were small in each group. If all learners were very similar, this would not obscure any effect present, but if individual differences are large then that would mask all but large effects. The data certainly indicate individual differences between pupils, but also large differences between occasions for the same pupil. It is not just that different levels of existing skill or aptitude in pupils are present, but that differential reactions to the stimulus and tasks seem to be as large.

Another type of explanation is that the measures were too insensitive, or failed to measure what is really important. The fact that we used the government required assessment criteria applied by an independent 
teacher means that, if this is true, it is not simply a failing of the study but of current practice and understanding of the topic of imaginative writing as a whole. This leads on to various questions important for further research as well as for practice.

Firstly, although we think of "creative writers" as those who both imagine original things, and describe them effectively for their audience, several distinct skills are involved. We followed other researchers in using the written output as the main product to measure, but that means that a creative child with poor written language skills could not be detected. Similarly for practice: if creativity is valued, then tasks independent of writing need to be set, taught, and fostered: for instance listening to oral accounts and scoring for the number of characters, events and objects mentioned that were not in the original stimulus or task description. Our observations of a few pupils who were stimulated by the VRE, then rather dampened by the blank sheet of paper, suggest this is an important issue.

Conversely practising and testing descriptive writing would most directly be done by providing a fixed stimulus, present during the writing, and scoring how much of it is expressed in writing. In fact there are further important intermediary skills involved. Both school tasks and psychology experiments have demonstrated that most people are unable to retrieve basic aspects of very familiar objects, i.e. objects "in" their memories. This can be demonstrated by asking someone to sketch the front of a post office letter box, showing the relationship of the slot, the boundary of the door that opens, and the signs that say when the next collection is; or by asking them how many windows the building they work in has. The VRE in our study seemed to give a vivid experience to the pupils, but for this to appear in their written work, they would have to internalise it, and then deploy this effectively in writing. This requires both memory skills and some kind of planning (making decisions about what to describe, and in what order or structure). Thus what we tend to describe as a single activity of "imaginative writing" has at least three different kinds of skill involved: creativity (imagining things not "given" in the task), retrieving and restructuring that material for the purposes of writing, and language skills.

It is partly an issue of designing new measures, since measures of the third stage of writing mainly in terms of the language used will of course neither describe nor focus attention on the necessary earlier stages of creativity and selecting what to express. But more importantly, this is an issue of whether researchers and educators should address these distinct skills separately or together. This is a form of the general issue of the advantages and disadvantages of training each subskill separately. The analogy with other tasks such as learning to read suggest that what works best is a combination of whole task practice in order to maintain its meaningfulness (reading for meaning, producing complete written stories), with separate subskill practice (phonics for reading, separating ideas generation from describing a fixed scene or event).

This line of analysis challenges whether our use of the VRE was in fact appropriate, despite its being approved by teachers and pupils. Even though our design rationale was that we would provide a setting for a story, not characters and events, the children did not invent the latter. Thus at best, the VRE gave them material for imaginative writing, but did not stimulate their creativity. This is perhaps what should be expected: rich sensory stimuli remove the need for imagination (in contrast to radio which, it is often remarked, strongly provokes imagination). In contrast, Robertson's work successfully requires her participants to make and test out creative decisions; furthermore it does so in a way largely independent of their language skills. However our VRE does not and may even tend to suppress it

On the other hand, our VRE may be a good stimulus to bypass that first stage, and subskill, of creativity, allowing more focussed practice at the next two stages of structuring (or "planning") and of actual writing. In that case, the next step would be to divide these remaining two stages and support them separately. The teacher's observation that two pupils seemed to write much faster after the VRE exposure suggests that there are some at least for whom the first creative step was the only bottleneck and the VRE addressed that, while 
those that seemed to hesitate over the blank sheet of paper may be blocked by the second stage of recall and structuring.

Our overall conclusion, then, is that the way forward for both research and practice may be to focus on the subskills involved in imaginative writing and to devote some classroom time, and perhaps some specialised technological tools, to practising each separately, while also preserving some time for the whole task activity. Creativity could be supported by its own exercises, as suggested in various materials for teachers as referenced above, or by a technological tool such as Robertson's, and its relevance to the overall curriculum aim of "imaginative writing" more clearly understood. The third stage of writing from a pre-determined plan is common in secondary schools, but its counterpart even for imaginative writing in primary schools should be developed. The middle (second) stage of effectively creating a plan i.e. selecting what is to be said, and structuring it, could use something like our VRE as the given starting point.

By using the existing data we intend to refine the design of the study and conduct a similar experiment in the schools' classrooms by using portable technology. This experiment was performed in a fixed VR installation with active stereo projection from the back of the screen. For a wider deployment, a more portable and lower cost solution is obviously desirable. A portable passive stereo projection system could easily be assembled using two inexpensive digital presentation projectors with polarisation filters mounted, a silver projection screen and inexpensive stereo glasses as commonly used in entertainment venues such as Imax 3D cinemas. Such a system could be clearly affordable to local authorities or larger schools.

\section{Acknowledgements}

The authors would like to extend their thanks to the staff of Digital Design Studio. The main financial support for this research project has been provided by NESTA (National Endowment for Science, Technology and the Arts) and Scottish Enterprise. The authors would like to thank the Education Department of West Dunbartonshire Council and the head teachers, teachers and pupils of the two primary schools for their valuable collaboration. Furthermore we would like to express our gratitude to ETH Zurich for providing the blue-c API.

\section{References}

Amabile, T. M. (1985). Motivation and Creativity: Effects of Motivational Orientation on Creative Writers. Journal of Personality and Social Psychology, 48, pp. 393-399.

Bobick, A., Intille, S., Davis, J., Baird, F., Pinhanez, C., Campbell, L., Ivanov, Y., Schütte, A. and Wilson, A. (1999). The KidsRoom: A Perceptually-Based Interactive and Immersive Story Environment. In PRESENCE: Teleoperators and Virtual Environments, 8(4), August 1999. pp. 369-393

Cruz-Neira, C., Sandin, D. J. and DeFanti, T. A. (1993). Surround-screen projection-based virtual reality: The design and implementation of the CAVE. In Proc. of SIGGRAPH '93, pp. 135-142.

Draper, S.W. (1998). Niche-based success in CAL. In Computers and Education. Vol. 30, pp. 5-8

Jelfs, A. and Whitelock, D. (2000). The notion of presence in virtual learning environments: what makes the environment "real". British Journal of Educational Technology, 31(2), pp. 145-152.

Johnson, A., Moher, T., Ohlsson, S. (1999). The Round Earth Project - Collaborative VR for Elementary School Kids. In Proc. of SIGGRAPH '99 abstracts and applications, LA, CA, Aug 8-13, pp 90-93.

Kim, P. (2006). Effects of 3D Virtual Reality of plate tectonics on fifth grade students' achievement and attitude toward science. Journal of Interactive Learning Environments, 14 (1), pp. 25-34

Marshall, P., Rogers, Y., Scaife, M. (2004). PUPPET: Playing and Learning in a Virtual World. International Journal of Continuing Engineering Education and Life Long Learning, 14(6), pp. 519-531. 
Naef, M., Staadt, O., Gross, M. (2004). Blue-c API: A Multimedia and 3D Video Enhanced Toolkit for Collaborative VR and Telepresence. In Proc. of ACM SIGGRAPH International Conference on Virtual-Reality Continuum and its Applications in Industry, VRCAI 2004, June 16-18, Singapore.

Prada, R., Machado, I. and Paiva, (2000). TEATRIX: Virtual Environments for Story Creation. In Proc. of Intelligent Tutoring Systems, 5th International Conference ITS 2000, June 19-23, Montreal, Canada, pp. 464-473.

Robertson, J. (2001). The effectiveness of a virtual role-play environment as a story preparation activity. Unpublished PhD thesis. University of Edinburgh .

Robertson, J. and Oberlander, J. (2002). Ghostwriter: drama in a virtual environment. Journal of Computer Mediated Communication 8(1).

Roussou, M. and Gillingham, M. (1998). Evaluation of an Immersive Collaborative Virtual Learning Environment for K-12 Education. American Educational Research Association Annual Meeting (AERA), April 13-17, San Diego, CA.

Roussou, M. and Slater, M. (2005). A Virtual Playground for the Study of the Role of Interactivity in Virtual Learning Environments. In Proc. of PRESENCE 2005: The 8th Annual International Workshop on Presence, September 21-23, London, UK, pp. 245-253.

Stanton, D., Bayon, V., Neale, Hl, Ghali, A., Benford, S., Cobb, S., Ingram, R., O’Malley, C., Wilson, J., Pridmore, T. (2001). Classroom Collaboration in the Design of Tangible Interfaces for Storytelling. Proceedings of the SIGCHI conference on Human factors in computing systems 2001, Seattle, US, pp. 482-489, ACM press.

Vygotsky, L.S. (1978). Mind in Society: the development of higher psychological processes. Harvard University Press, Cambridge, MA.

Watson, B., Kim, J., McEneany, T., Moher, T., Hindo, C., Gomez, L. and Fransen, S. (2004). StorySpace: Technology supporting reflection, expression, and discourse in classroom narrative. IEEE Computer Graphics and Applications, 24 (2), pp.13-15.

Winn, W.: The Impact of Three-Dimensional Immersive Virtual Environments on Modern Pedagogy. (Technical Report) Human Interface Technology Lab, Seattle (1997)

Winn, W.D. (2002). Keynote Address: What can students learn in virtual environments that they cannot learn in class? Presented at First International Symposium, Open Education Faculty, May 2002, Anadolu University, Turkey.

Youngblut, C. (1998). Educational Uses of Virtual Reality Technology. Technical report IDA, Document D2128, Institute for Defense Analyses, Alexandria, Virginia. 